$$
\begin{array}{r}
\text { Só se pode viver perto } \\
\text { do outro, e conbecer } \\
\text { outra pessoa, } \\
\text { sem perigo de ódio, se a } \\
\text { gente tem amor }
\end{array}
$$




\title{
Dão-Lalalão, a reescrita do desejo
}

Biagio D'Angelo ${ }^{1}$ I Universidad Católica Sedes Sapientiae - Lima

Resumo: Embora a obra de Rosa dedique um espaço importante ao problema amoroso e erótico, não são muitos os estudos dedicados ao romance breve Dão-Lalalão, onde as personagens Soropita e Doralda vivem e experimentam um amor carnal, perfeito, esponsal, que lhes permite alcançar a perfeição do desejo. Rosa reescreve o desejo, não como obstáculo ou limite à perfeição da alma, nem como separação maniquéa entre o corpo impuro e o espírito afastado do corpo, mas como saudade última de bem, de satisfação, de radicalização da realidade. Palavras-chave: Desejo, Eros, Soropita.

\author{
Alli me mostrarias \\ Aquello que mi alma pretendia, \\ Yluego me darias \\ Alli tú, vida mía, \\ Aquello que me diste el otro día. \\ (Juan de la Cruz, Cántico espiritual, XXXVIII)
}

1. Biagio D'Angelo é Professor de Literatura Comparada e Estética (Universidade Católica Sedes Sapientiae, Lima, Peru). Coordenador do Mestrado em Literatura e Cultura Brasileiras da mesma universidade, conjunto com a Universidade Nacional Maior de São Marcos, é vicepresidente da Associação Peruana de Literatura Comparada). Tem publicado sobre literatura brasileira (Guimarães Rosa, Machado de Assis, Clarice Lispector) e sobre questões de teoria literária (em particular, sobre a relação texto-imagem e meios de comunicação). Seu último livro é Borges no centro do infinito, Lima, Fondo Editorial UNMSM, 2005. 
A obra de Guimarães Rosa dedica um espaço notável ao problema amoroso e erótico: com o caso de Reinaldo-Diadorim, por exemplo, as reflexões e os momentos perturbadores da lógica mental de Riobaldo, que se estima um jagunço inviolável e "privilegiado", ultrapassam o terreno do insondável e do mistério afetivo da alma humana; a história de Buriti, um relato quase "noturno", como o mesmo título da obra em que está incluído deixa prever (Noites de sertão), representa outra fase da leitura e análise da sensualidade que sustenta o interesse da investigação rosiana, sendo o "Buriti", um "bom lugar", "uma necessidade", o descobrimento e a confirmação que "o sertão é da noite" (ROSA, 2001, p. 119). Contudo, são poucos os estudos dedicados ao eros e ao amor na obra rosiana: um artigo magistral como "O amor na obra de Guimarães Rosa", de Benedito Nunes (NUNES, 1976, pp. 143-171) poderia considerar-se, certamente, exaustivo, mas a obra de Guimarães Rosa, que se funda numa pluralidade de interpretações, de hipóteses, de aventuras inteletuais, deixa outro espaço para leituras renovadas, nas quais a temporalidade insere-se como eixo modelador de ulteriores paradigmas.

"Obra que procura a objetividade", declara Finazzi Agrò da narrativa rosiana, "que pretende a perfeição do absoluto e que, no entanto, deve lidar com a imperfeição da subjetividade e com a parcialidade da experiência" (FINAZZI AGRÒ, 2001, p. 47). De fato, utilizaremos como ponto de partida de nossa reflexão essas palavras, que estão pensadas e escritas para um comentário à obra-prima de Rosa, Grande Sertão: veredas. Trata-se de um juízo muito pertinente também se pensamos à experiência relatada em Corpo de Baile, e em particular, o que aqui mais nos interessa, ao romancepoema Dão-Lalalão. O título provê de uma antiga cantilena infantil, difundida nos países de língua portuguesa, que reaparece, sub-repticiamente, no texto rosiano, como epígrafe: no "coco da festa do Chico Barbós", os desejos infantis se transformam, amadurecem, e a reiteração do verbo "querer" ritma a pulsão antropológica de desejar tudo em um frenesi existencial que responde da plenitude da vida própria: "Da mulher quero o sapato, quero o pé! / - quero a paca, quero o tatu, quero o mundé..." (ROSA, 2001, p. 27). O título não é novo já que se encontra na "Estória de Lélio e Lina", outra perturbante investigação do amor como consigna pura e gratuita do eu ("O amor era isso - lãodalalão - um sino e seu badaladal", ROSA, 2001 b, p. 301).

O universo de Dão-Lalalão é o sertão mineiro, alegoria e ficção da existência, de seus rasgos sociais, históricos e metafísicos. A temporalidade 
é determinada pela presença do rádio, através do que Soropita ouve a novela (onde as grandes paixões e os grandes desejos são curiosamente representados no estádio mais extremo e instintivo). A novela no rádio não significa apenas uma referência temporal, que reafirma a colocação histórica do relato, mas uma alegorização do espaço da memória na vida do protagonista. "A memória de Soropita está cheia de lembranças terrenas" e, como na novela do rádio, essas imagens deturpam o desenvolvimento claro, límpido da existência dele e de Doralda, porque são associados ao nível do instinto, do passado angustiante e mórbido, de uma infelicidade que pode levar até a morte: "Sua memória, seu pensamento e sua vontade estão presos ao mundo terreno - a seu mundo terreno, à sua pessoa. Estão presos à terra e à sua opacidade e trevas" (ARAÚJO, 1996, p. 513). Soropita, assim como Doralda, se movem, portanto, da obscuridade de uma memória destruidora à luz irresistível da pulsão pela unidade e, daí, pela superação da dicotomia terrenal/espiritual. Nesse sentido, Soropita e Doralda não são apenas personagens "regionalistas"; são sertanejos e portanto, na óptica rosiana, universais. O que move Soropita é o mesmo movimento especular da mulher dele: a paixão. Em Soropita as paixões são pulsões irresistíveis, que pertencem ao mundo do verdadeiro porque decorrem de longe, da noite do tempo, da noite do sertão. Sentimentos de ciúme, de inveja, os crimes que ele aprontou, constituem a "sombra" com que ele arrasa a vida rutinária e obscura nas veredas e entre os buritis do sertão. É a sombra plotiniana que Rosa propõe como epígrafe da inteira obra e que deixa perceber que a própria narrativa representa a dinâmica, o processo de conhecimento e de possível solução da identidade: "Porque em todas as circunstâncias da vida real, não é a alma dentro de nós, mas sua sombra, o homem exterior, que geme, se lamenta e desempenha todos os papéis neste teatro de palcos múltiplos, que é a terra inteira" (ROSA, 2001, p. 5). Como Soropita e Doralda, geralmente as personagens de Guimarães Rosa sofrem o sentimento escandaloso da vida, a dor (barroca) de ver a opulência da vida misturada às profundidades dos mistérios e dos gestos sagrados do homem. Soropita e Doralda são apresentados sempre in media res. "Dela, dele, da vida que separados tinham levado, nisso não tocavam, nem a solto fio - o sapo, na muda, come a pele velha" (2001, p. 49): Soropita e Doralda já viveram, já experimentaram, já conhecerem o abismo da noite obscura da alma, parafraseando os versos célebres de São João da Cruz. Eles se escolheram porque similares, porque reconhecidos, um dentro da outra, estão dentro de 
uma estrada de necessárias transformações. Por isso, eles todos "dalalalam", como sugere o próprio enigmático título da obra, ou seja, estalam, crepitam, como línguas de fogo e como impacientes e ansiosos peregrinos do sertão.

In media res. Há sempre uma mancha preta que angustia quando a narração nos é proposta in media res, no meio das coisas que já aconteceram e que o leitor, se não sabe, pode apenas suspeitar. No regresso para casa, Soropita oscila entre a contemplação da natureza sertaneja, de seus sons, seus pássaros, o dalalalar das folhas e das ervas, e a enigmática pressão que pesa no coração dele. Traz armas e cicatrizes, mas desses o narrador omnisciente prefere não falar no começo. É certo que Soropita esconde manchas, assim como as armas e as cicatrizes. O passado incerto, misterioso de Soropita (ao largo da narração, chamado também de outras formas, como Surrupita, por amigos antigos e vaqueiros) contrasta com o passado "aberto", claro (e lunar ao mesmo tempo) da mulher, Doralda, uma prostituta, que ele, provavelmente, resgatou de uma vida deteriorada e sem saída. A viagem de volta para a casa é a ocasião para que Soropita lembre a própria vida passada, busque uma forma de procurar se a própria identidade sofreu mudanças, sobressaltos, desejos enfraquecidos ou satisfeitos. Soropita gosta(va) de mulheres da vida. Doralda é uma delas. Agora, ele parece estar intentando renegar les neiges d'antan, como na melhor balada de François Villon, fruto de uma Idade Média medieval e sertaneja ao mesmo tempo, mas o desejo de negação é suplantado pelo desejo de reafirmação do eros e do vigor da juventude relaxada. A chegada de Dalberto, velho amigo de trabalho e de bordéis, confirma, em Soropita, a inexorabilidade dos eventos acontecidos, e a responsabilidade que deles surge. Voltando à casa com Dalberto, convidado a passar um momento descontraído para que conheça Doralda, Soropita é continuamente suscitado a repensar ao passado, ao reatar os fios da memória que ele esqueceria porque tenebrosos, negativos. O passado ("um passado que, se a gente auxiliar, até Deus mesmo esquece”, 2001, p. 31) continua ameaçando a felicidade do presente e Soropita é bem consciente que não se

2. Se veja, a esse propósito, o verbete "Dalalalar" citado em SANT'ANNA MARTINS, Nilce, O Léxico de Guimarães Rosa, 2 ed. São Paulo, Editora da Universidade de São Paulo, 2001, p. 147. "Dalalalar: Aquilo bonito, quando tição aceso estala seu fim em faíscas - e labareda dalalala" (Grande Sertão: Veredas, 238/293). / ND. Estalar, crepitar. // Voc. onom. que sugere o ruído das labaredas bem como, pelo seu grafismo, lembra as línguas de fogo". 
deve apenas por ter casado uma mulher da vida, uma espécie de Madalena arrependida; é, também, o peso da morte que pesa nele. A conversa dos vaqueiros, encontrados com Dalberto, põe em evidência a culpa de Soropita: "- Vocês sabem quem aquele é?: Surrupita! (...) Ele, o diabo dele (...) O que matou Antônio Riachão e o Dendengo... o que matou João Carcará!” (ROSA, 2001, p. 55). O autoconhecimento de Soropita é ofuscado também pelas imagens que os outros constroem dele como implacável assassino. Outra culpa, in media res; outra mancha que se deseja borrar, embora borrando-a, intenta-se borrar as origens, o fluxo do que já foi e já previsto.

Contudo, a culpa, no sentido de imperfeição, de falta, de ausência de uma completude definitiva, relaciona-se com o anseio de alcançar a sua forma, o seu espaço totalizante: a perfeição, a unidade, o completamento realizam-se no gesto duplo e multifacetado do eros e do amor. Rosa trabalha com Soropita e Doralda dentro dessa dimensão misteriosa e, ao mesmo tempo, erótica, depurando o amor da carga do "possesso", da violência sobre o outro, da possessão que domina nos sentimentos e depaupera o amor e o eros do aspecto místico de milagrosa conjunção carnal e espiritual. É por isso que Guimarães Rosa afirma ter disseminado em Noites do Sertão referências intertextuais, ecos, reescritas paródicas e, talvez, escandalosas, do Cântico dos cânticos bíblico. As páginas que ele dedica à explicação dos conceitos que subjazem ao palimpsesto dos romances Dalalalão e Buriti representam não apenas a enorme cultura rosiana, mais também a intenção autoral de deixar perpassar na obra essa evidente paráfrase da Bíblia (ROSA, 2003, p. 8082). A comparação com o Cântico dos Cânticos vincula-se perfeitamente com Dalalalão, em particular, e com a obra de Rosa em geral. De fato, ambas escritas se apresentam como fortemente alegóricas: por um lado, o amor de Deus para Israel e o do povo israelita para seu Deus são percebidos dentro da relação de um casal, um tema que se pode achar em outros livros do Velho Testamento (como o profeta Osea); por outro, a imagem de um casal amante alude à união mística da alma com Deus, conforme a fórmula famosa do casamento místico que será retomado por grandes poetas religiosos e metafísicos como Dante, João da Cruz, John Donne. Como o Cântico dos Cânticos, Dalalalão alegoriza a exaltação do amor profano, subvertendo essa mesma definição limitada e limitante. A celebração do amor recíproco e fiel, sigilado pelo gesto do matrimónio, proclama, na realidade, a legitimidade e a fecundidade do amor humano: assim, seria impossível e improvável falar de 
amor "profano", já que não existiria nenhuma ação pró-fana (ou seja, fora do sagrado, fora do templo): também em Guimarães Rosa, o gesto divino do casamento permite abençoar e santificar qualquer gesto "acontecido", qualquer gesto realizado na história em nome da fidelidade e da reciprocidade amorosa (em um sublime momento de charitas laica e cristã). O agapé de Soropita e Doralda, descrito em páginas de intenso erotismo e de magnifica textura poética, deriva da consciência da união como fogo de caridade em busca de uma unidade eterna; o amor deles constitui uma associação efetiva e afetiva da estabilidade do homem e da mulher, ou dos entes ou dos sujeitos que, embora sem esquecer a mancha da culpa ou do mal cometido, se lançam ao desejo de uma possessão mais verdadeira e completa. "- Todo o mundo gostava de você... Tu é a bebida do vinho... Ah, então você gostou de mim por que? [...] Tanto fui te vendo Bem, deduzi: este é o meu, que é, sem a gente se saber... Eu gostei na certeza" (2001, p. 101). A vida sexual de Soropita e Doralda, mais que alegorizada, é, no relato, demitologizada e considerada uma sã realidade: a dignidade e a bondade do amor e do eros logram aproximar dois corpos e, portanto, como se diz na linguagem quotidiana, duas almas: isso exorciza os mitos pagãos que estão relacionados à vida sexual e resgata o gesto do puritanismo banal e do erotismo falso e vulgar. Os pedaços incompletos, os fragmentos das múltiplas variações que integram os corpos recompõem dessa maneira: "O casamento, para Soropita, significa uma recomposição de si mesmo, uma unificação de si, reunindo os pedaços" (ARAÚJO, 1996, p. 507). O que vence aqui é a realidade crua, não a transposição no terreno das ideias: o amor (não a paixão dos sentidos, reduzida a mero instinto) é a celebração paradoxal da união metafísica no plano do físico.

Mas não apenas o Cântico dos Cânticos é a referência intertextual mais comprometida no relato: Dante e a Comédia (principalmente ao canto V do Inferno, o dos luxuriosos) e as imagens bíblicas do Apocalipse, são alusões admitidas pelo próprio Rosa declara na correspondência com Edoardo Bizzarri: "foi intencional tentativa de evocação, daqueles textos clássicos formidáveis, verdadeiros acumuladores ou baterias, quanto aos temas eternos" (2003, p. 86). O efeito seria de inoculação de "sub-para-citações", afirma jocosamente o autor, "células temáticas, gotas da essência, esparzidas aqui e ali, como tempero" (pp. 86-87), um pano de fundo que evoca a totalidade medieval da unidade corporal com o espiritual. Eticamente, Rosa insiste, sob ressonâncias subliminais, na alegoria do desejo erótico, como alegoria do desejo de plenitude 
do ser. Para Rosa não existe desejo que precisa ser domesticado. A subjugação do desejo, além de ser uma frustração, possui uma lógica de "falência", porque se suspende ou se censura sempre uma parte do ser, reduzindo as vivências humanas a uma perigosa dicotomia de boas e más ações. Rosa convida, portanto, a uma medievalização do desejo, à sua radicalização, porque no fundo dele tem a proposta de uma "totalidade" da pessoa. Não seria ousado dizer, além disso, que Rosa tenta uma "totalidade" ou uma reunificação em termos filosóficos entre a erótica platônica e o cristianismo. Se o cristianismo, interpretado à luz da filosofia moderna e positivista, rejeitou o edonismo e procurou uma cisão entre corpo e alma, entre intelecto e sensibilidade, entre mundo sensível e mundo supra-sensível, para Rosa se trataria, portanto, de uma reescrita do desejo, à que pode chegar, justamente, a operação narrativa e estética: a busca nas coisas terrenas é um veículo para a ascese até o Belo, que participa, em diferente medida, de cada coisa. Para Platão já está presente uma separação entre corpo e alma, de uma caducidade do corpo (que seria, nele, prisão da alma) que vai se liberar de sua própria condição com a morte, começo da vida verdadeira. Nas palavras de Platão, de fato, aprender a filosofar significa aprender a morrer. E para Soropita, aprender a aceitar as paixões que agitam no homem significa aprender a vida no seu valor ontológico, responder ao desejo de unidade e da feroz pulsão do Um (poderíamos dizer parafraseando Severo Sarduy): "Por que, então, o corpo da gente não obedecia à vontade da cabeça, sempre e em tudo por tudo - como devia de ser: as partes, deviam de estar sempre sentindo e fazendo, com prazer de mocidade, o que a gente mesmo quer" (2001, p. 105). A carnalidade, parece sugerir Rosa com esse personagem, não deve ser interrompida, a dimensão "noturna" da alma deve ser aceita, vivida, amada como ponto de arranque da própria humanidade. O "eros" platônico é superior à poesia, mas em Guimarães Rosa, o eros precisa, ao contrário, da forma narrativa ou da estética para poder liberar-se das impurezas que deturpam o desejo de totalidade. Soropita bem sabe desse assunto delicado e necessário, que implicava a dramaticidade da existência, o puro no impuro: "E ainda mais forte sutil do que o pedido do corpo, era aquela saudade sem peso, precisão de achar o poder de um direito bonito no avesso das coisas mais feias" (2001, p. 67). A "saudade sem peso" e o "direito bonito no avesso" do feio indicam o paradoxo do desejo verdadeiro, que precisa sujar-se para enxergar nele a perspectiva final que dá sentido e naturalidade às coisas mais ocultas e misteriosas. O desejo "se mexe com 
muitas cores", "em muitas trevas", propõe sugestivamente Guimarães Rosa, e "Deus podia ter botado os cegos no mundo, para vigiarem os que enxergarem. Esses cegos, como os brabos arruaceiros: os valentões, que eram mandados permitido como castigo de todos, para destruir o sensível do bom sossego" (2001, p. 64). O que destrói o sensível é o que o gera novamente.

O eros representa, em conjunto com a dimensão psíquica e a potência do desejo, a capacidade de encontrar no outro o similar e o diverso. Dai a dúplice natureza etimológica do termo "desejo", similar e diverso ao mesmo tempo, contemplativa e aporética: "desejar" (o seu sinônimo "almejar", por exemplo, doa perfeitamente a idéia da alma - almejante - que sai de si mesma em busca de satisfação) deriva, como é notório, do latim "de-siderar" ("sidera", estrela) que pode equivaler a "fixar atentamente as estrelas" (com "de" em valor intensivo, acrescentado), assim como "faltar, carecer das estrelas" (com "de" em posição de negação ou de afastamento), aquela saudade que Doralda experimenta com Soropita, apesar de toda a experiência erótica vivida em outros momentos, e que o amigo Dalberto percebe, em uma discussão íntima com Soropita, como um dos momentos de plenitude almejados por todo homem, que "viaja, padecendo": "Mas você aprova comigo: só quando se está com mulher é que a gente sente mesmo que está lorde, com todos os perdões... Que é que se está vivendo, mesmo. Afora isso, tudo é poeira e palha, casca muida" (2001, p. 65). Para Dalberto, em efeito, o amor é um desejo que não consegue ser recheado por completo e, como fogo inextinguível, mantém em vida a coragem do homem: "Amor é sede depois de se ter bem bebido" (2001, p. 94).

A vida plena, o objetivo constitui o verdadeiro êxtase, a exaltação do espírito, que, no ato próprio de ir fora de si, reconstrói o sentido caçado e questionado da existência. Soropita mesmo sabe que no desejo de regressar à casa, no desapear do cavalo, se manifesta a satisfação última, provisória e, contemporaneamente, definitiva: "A felicidade é o cheio de um copo de se beber meio-por-meio; Doralda o esperava" (2001, p. 42); "Doralda era sua fome pedida, nem os salteios do dia, de fadiga, pareciam deixar rastro, a vida era um vibrar de coisa, uma capacidade" (2001, p. 98). Por isso, no final da narração rosiana, a presença de Doralda, o regresso à casa, são pontos cardinais de uma "paz poderosa" que vem da carnalidade do desejo, da sua não-censura e, ao mesmo tempo, da sua perspectiva de certeza final. A reescrita do desejo em Rosa coincide com um desejo que solicita uma adesão mais comprometida 
com a realidade, com um desejo - carnal e espiritual - que, fora da lógica dicotómica, não é obstáculo, nem limite, mais profundidade para que tudo seja perfeito (feito para ser cumprido, realizado, satisfeito): "A vida podia recomeçar, igualzinha, do princípio, e dali, quantas vezes quisesse" (2001, p. 115).

Resumen: Aunque la obra de Rosa dedica un espacio importante al problema amoroso y erótico, no son muchos los estudios dedicados a la breve novela Dão-Lalalão, en el que los personajes Soropita y Doralda viven y experimentan un amor carnal, perfecto, nupcial, que les permite alcanzar la perfección del deseo. Rosa rescribe el deseo, no como obstáculo o límite a la perfección del alma, ni como separación maniquea entre el cuerpo impuro y el espiritu alejado del cuerpo, sino como nostalgia última de bien, de satisfacción, de radicalización de la realidad.

Palabras Clave: deseo, Eros, Soropita.

\section{Referências Bibliográficas}

ARAÚJO, Heloisa Vilhena de. O roteiro de Deus. São Paulo: Mandarim, 1996.

FINAZZI AGRÒ, Ettore. Um lugar do tamanho do mundo. Tempos e espaços da ficção em João Guimarães Rosa. Belo Horizonte: Editora UFMG, 2001.

NUNES, Benedito. O dorso do tigre. 2. ed. São Paulo: Perspectiva, 1976, pp. 143-171.

ROSA, João Guimarães. Noites do sertão. 9. ed. Rio de Janeiro: Nova Fronteira, 2001.

ROSA, João Guimarães. No Urubuquaquá, no Pinhém. 9. ed. Rio de Janeiro: Nova Fronteira, 2001b.

ROSA, João Guimarães. Correspondência com seu tradutor italiano Edoardo Bizzarri. 3. ed. Rio de Janeiro: Nova Fronteira, 2003.

SANT'ANNA MARTINS, Nilce. O Léxico de Guimarães Rosa. 2. ed. São Paulo: Editora da Universidade de São Paulo, 2001. 